\title{
Holocene Climatic Variability Inferred from Lacustrine Deposits in Arid China
}

\author{
Fa-Hu Chen ${ }^{1,2}$, Bo Cheng $^{1}$, Cheng-Bang An ${ }^{1}$, Yan Zha0 ${ }^{1}$, Jia-Wu Zhang ${ }^{1}$, David B. Madsen ${ }^{3}$, Zicheng Yu and Yan Zhu $^{1}$ \\ ${ }^{1}$ CAEP, MOE Key Laboratory of West China's Environmental System, Lanzhou University, Lanzhou 730000, China; fhchen@|zu.edu.cn \\ ${ }^{2}$ CAS Key Laboratory of Desert and Desertification, CAREERI, Lanzhou 730000, China \\ ${ }^{3}$ Texas Archeological Research Laboratory, University of Texas, Austin, TX 78712, USA \\ ${ }^{4}$ Department of Earth and Environmental Sciences, Lehigh University, Bethlehem, PA 18015, USA
}

The arid history of the Holocene interglacial could provide an analog for future climatic variations in the interior of the Eurasian continent. Previous research has revealed an unstable climate with distinct periodicity (O'Brien et al., 1995) and rapid change events (Bond et al., 2001) that are probably of global scale (Mayewski et al., 2004). In Chi$\mathrm{na}$, the prevailing concept is that a wet and warm period, the so-called "Holocene Optimum", existed in the mid-Holocene across China (Shi et al., 1994), during which the area had high precipitation and a humid climate. However, recently published data suggest a geographic differentiation of the Holocene climate in arid and semi-arid China (An et al., 2005). Here we attempt to further address this issue by reporting lacustrine depositional records in arid China that support our previous finding that the Holocene climate in arid and summer monsoon margin regions was generally unstable, with a very strong drought during the mid-Holocene (Chen F. H. et al., 2003). Lacustrine sediment cores from Juyanze Lake and Zhuyeze Lake in the south Mongolian Pla-

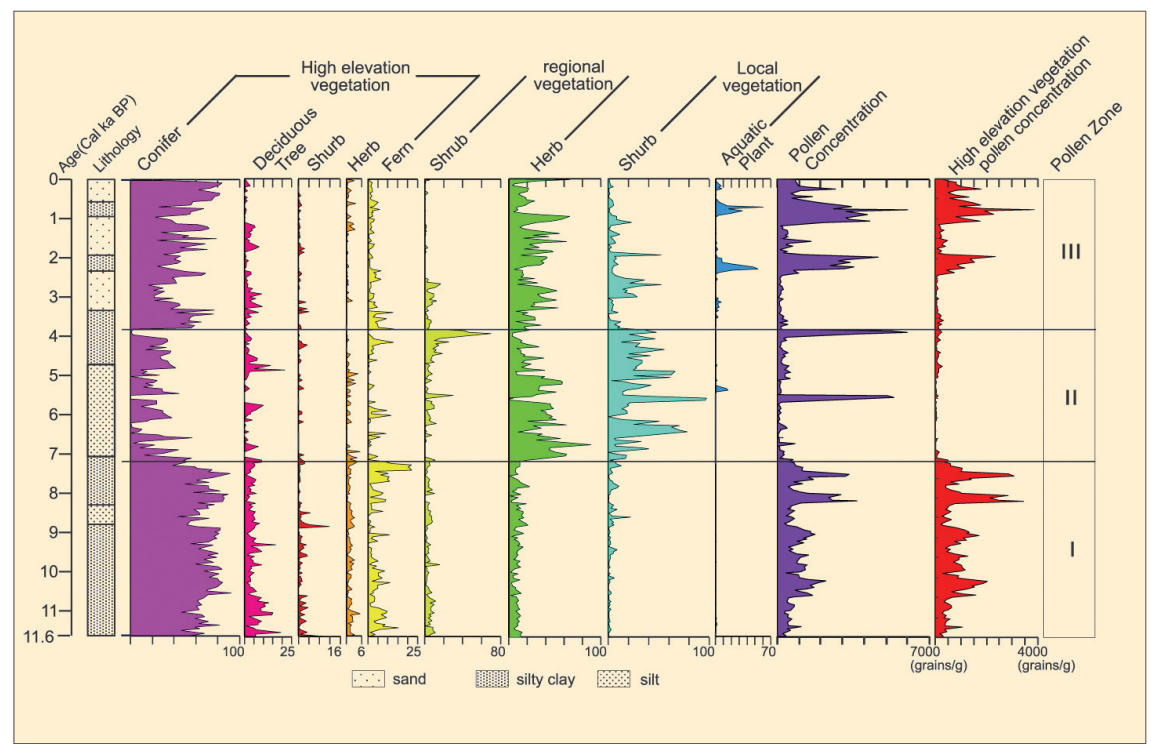

Fig. 2: Pollen diagram from Zhuyeze Lake (SJC section) presented ecological groups, with calibrated age. Pollen concentrations and pollen zones are also shown.

teau, and Bosten Lake in the Tarim

Basin, were collected to reconstruct climatic variations during the Holocene.

\section{Geographical Settings and Laboratory Methods}

Bosten Lake $\left(86^{\circ} 41^{\prime}-87^{\prime} \mathrm{E}, 41^{\circ} 56^{\prime}\right.$ $42^{\circ} 14^{\prime} \mathrm{N}$ ) is the largest freshwater body in arid China, adjacent to the largest desert in China, the Taklimakan. Both Juyanze Lake

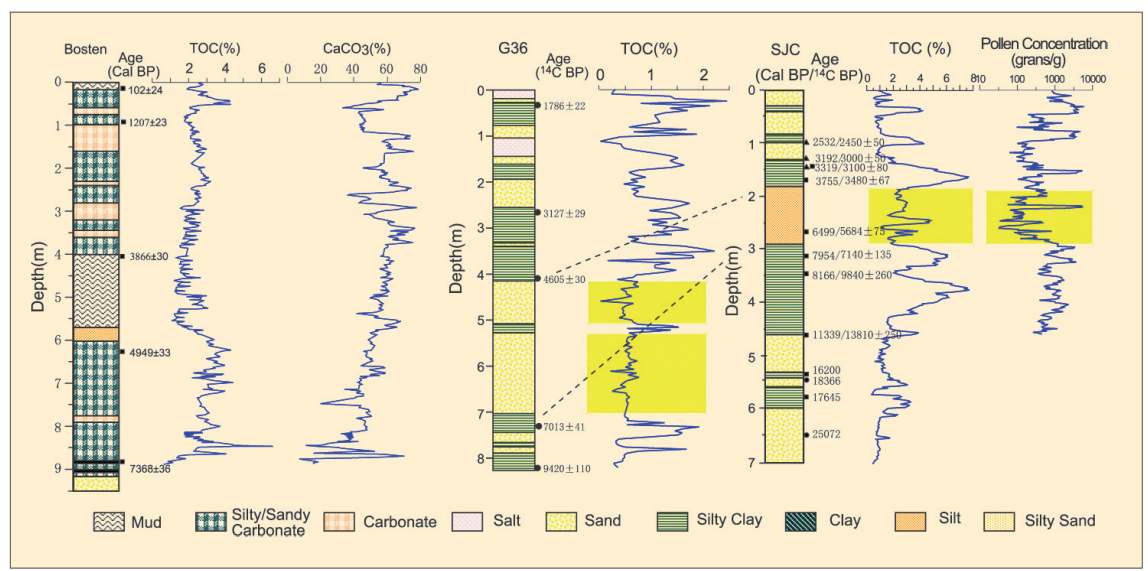

Fig. 1: The lithology and proxy variations of Bosten Lake, Juyanze Lake (G36 core), and Zhuyeze Lake (SJC section). Radiocarbon dates are alongside the lithological column (squares = terrestrial plant remains or pollen concentrates; circles = bulk organic matter). The dates from bulk organic matter at SJC have been corrected by 530 years to account for a carbon reservoir effect (Chen F.H. et al., 2003). The shaded areas indicate the mid-Holocene dry event and generally shallow lakes around ca. 7-5 cal yr BP. Dashed lines show the correlation between different lakes. $\left(101^{\circ} 34^{\prime} \mathrm{E}, 42^{\circ} 00^{\prime} \mathrm{N}\right)$ and Zhuyeze Lake $\left(103^{\circ} 20^{\prime} \mathrm{E}, 39^{\circ} 00^{\prime} \mathrm{N}\right)$ are terminal lakes of rivers originating on the northern side of the Qilian Mountains. These lie on the present margin of summer monsoon regions in arid western China. The average annual precipitation near these three lakes is less than $100 \mathrm{~mm}$.

The lithology of the Bosten Lake core is shown in Figure 1. Sediment samples were taken every $2 \mathrm{~cm}$. TOC and $\mathrm{CaCO}_{3}$ content were analyzed using two methods: loss on ignition (LOI $550^{\circ} \mathrm{C}$ and LOI $880^{\circ} \mathrm{C}$ ) (Ströhlein instrument). Five radiocarbon-AMS dates on terrestrial plant residues provide age control. Core G36 was drilled on the flat lake floor of Juyanze Lake. Lithology varies within the core, with frequent alternations of clay, silt/sand and salt. Five radiocarbon-AMS dates on terrestrial plant remains indicate that this core covers almost all of the Holocene (Fig. 1). TOC was analyzed at $2-5 \mathrm{~cm}$ intervals using the same method as samples from Bosten Lake. The lacustrine sediment at the SJC section, located at the western margin of Zhuyeze Lake, consists of siltyclay, silt and sand, with thin black 
layers of high organic matter. The chronology of this section is established by thirteen radiocarbon dates that show the base of the section dates to the Last Glacial Maximum, while the upper $4.6 \mathrm{~m}$ formed during the Holocene (Chen F.H. et al., 2003). Standard pollen analysis techniques were used to analyze 232 pollen samples collected at 2cm intervals (ca. $50 \mathrm{yr} / \mathrm{sample}$ ) for the Holocene. With some exceptions, over 300 pollen grains and spores per sample were counted.

\section{Results and Discussion}

Variations of proxies obtained from these three lake cores are shown in Figure 1. Figure 1 clearly shows that TOC generally declined but $\mathrm{CaCO}_{3}$ generally increased during the Holocene in Bosten Lake. It is safe to say from the sandy lithology that the early Holocene (before about $8.5 \mathrm{yr} \mathrm{BP}$ ) is characterized by a dry climate. More detailed and accurate analyses are ongoing. The TOC of core G36 illustrates the stratigraphic variation: clay/silt corresponds to high TOC values, while sand/salt corresponds to low TOC values, indicating that the drilling site was covered by alternations of deep water and shallow water from 9420 to 6500 14C yr BP. Very shallow water, as shown by littoral sand-silt and fluvial sand, was deposited between 6400 and 4605 ${ }^{14} \mathrm{C}$ yr BP. Deep water returned and lasted until $3120{ }^{14} \mathrm{C}$ yr BP, with alternations of shallow water, salt deposition, a deepening lake and dry conditions throughout. In the SJC section, over 50 pollen taxa were identified in the samples. Based on the relationship between pollen assemblages and the distribution of modern vegetation in the drainage, the pollen taxa can be divided into three ecological groups: high-elevation vegetation taxa coming mainly from the forest vegetation zone; regional vegetation taxa, and; the local vegetation taxa coming mainly from the desert vegetation zones (Zhu et al., 2003). Pollen concentrations were generally high in the early Holocene before 7000 cal yr BP but had century-scale variations (Fig. 1). Large-scale variations can

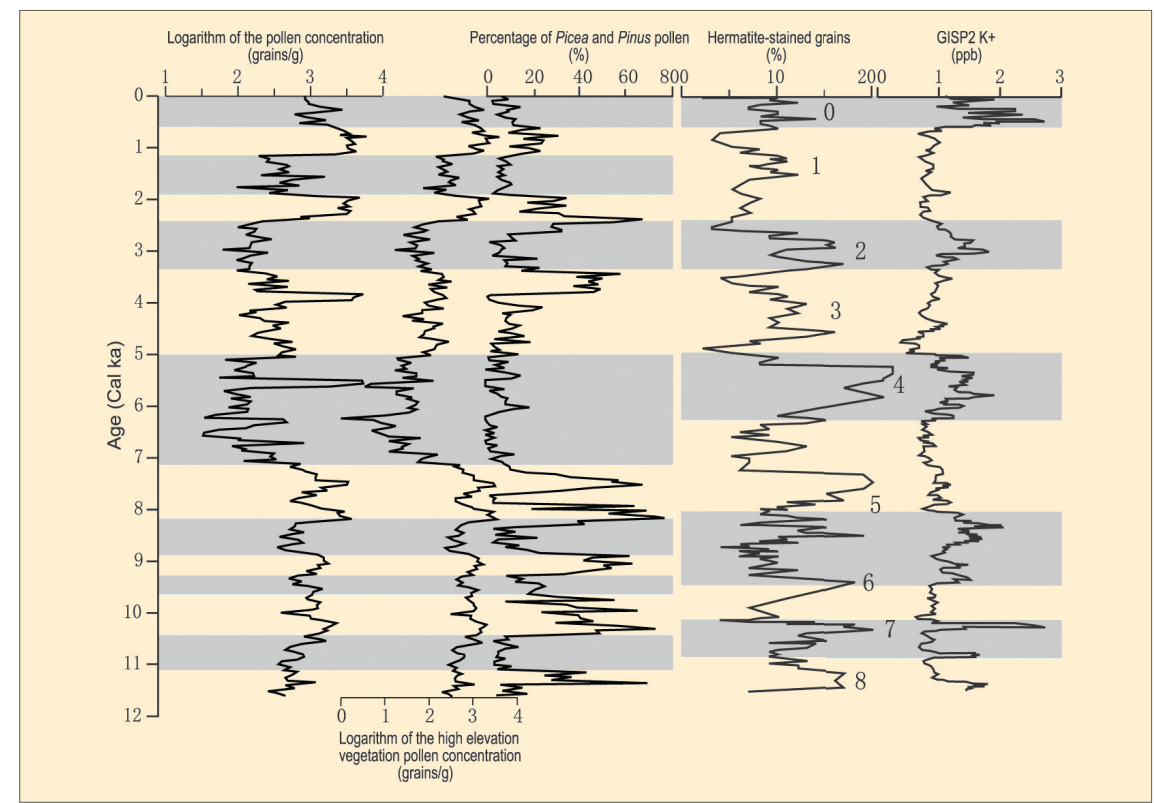

Fig. 3: Correlation of total pollen concentrations, high-elevation vegetation pollen concentrations and Picea-Pinus percentages at the SJC section with percentages of hematite-stained grains of Core VM29-191 in the Northern Atlantic Ocean (Bond et al., 2001) and potassium ion content in the GISP2 ice core (Mayewski et al., 1997). The episodes of high hematite-stained grain counts are marked in sequence from No. 0 to No. 8, (right panel, Bond et al., 2001). The shaded areas indicate weak summer monsoon and thus dry climate events in the study area, and periods of a strong Siberian High.

be seen in the concentration curve, with three minima at 7000-5000 cal yr BP, ca. 3000 cal yr BP, and ca. 1200 cal yr BP, separated by three peaks of relatively high concentration (Fig. 1 and Fig. 2).

Three pollen zones during the Holocene period can be clearly shown in the pollen assemblage (Fig. 2).

Zone I: (460-282 cm; 11.6-7.1 ka): The pollen concentration of this zone is the highest in the entire section, with a peak value of 2,0003,000 grains $/ g$ and a mean value of 400-1,500 grains/g. Conifer pollen, mainly Sabina, Picea and Pinus, which contribute $50-90 \%$ of the pollen sum, dominates the pollen assemblages (Fig. 2). In the highelevation pollen group, broadleaf tree pollen also has a relatively high value of between $1 \%$ and $11 \%$, while regional and local pollen have quite low percentages.

Zone II: (282-152 cm; 7.1-3.8 ka): Pollen concentrations, especially those of high-elevation pollen, are at their lowest value for the entire section. Xerophyte pollen dominates the pollen assemblage and is at its peak for all of the Holocene. Regional vegetation pollen also has high percentages, while conifer polIen decreases to a low value (Fig.
2). Nitraria pollen increases to $90 \%$ in some samples. The remarkably high pollen concentrations, with values reaching 5,000 grains/g in exceptional layers, is due to the rapid growth of xerophytes, especially desert plants such as Nitraria, indicating a possible dry lake at the section site for a short period.

Zone III: (152-0 cm; 3.8-0 ka): Pollen concentrations vary greatly in this zone (Fig. 2) and there are two types of pollen assemblages. One type is similar to Zone I, with a pollen assemblage dominated by conifer pollen in a range of $38 \%$ to $80 \%$, and with high pollen concentrations 2.4-1.9 cal ka and 1.1-0.5 cal ka. The other type is similar to Zone II, with a pollen assemblage dominated by steppe and xerophyte pollen and relatively low pollen concentrations (Fig. 2). A difference from Zone II is that conifer pollen in these layers continues to be $11-70 \%$ but is mainly Sabina pollen, from a tree that prefers a drier climate than does Picea in this region.

The pollen record from the SJC section indicates that the climate in the early Holocene (11.6-7.1 cal ka) and late Holocene (3.8 cal kapresent) was humid and markedly variable. There was a generally dry climate in the area during the mid- 
Holocene with a decreasing summer monsoon. In arid northwest China, high Holocene lake shorelines normally date to before $7 \mathrm{cal} k \mathrm{ka}$. This accords with a period of high lakelevels reported from Mongolia and central Asia (e.g. Lehmkuhl and Lang, 2001; Grunert et al., 2000). The strongest drought interval, shown clearly in Figure 2, was from 7.2 cal ka to about 5.0 cal ka. Generally, lakes in the southern Mongolian Plateau were found to have undergone low lake levels or even dry lake bed sequences during the mid-Holocene (Chen C-T. A. et al., 2003). In addition, a Holocene soil (paleosol $\mathrm{S}_{0}$ ) was interrupted by a dust deposit layer around $6 \mathrm{ka}$ ago in the Chinese Loess Plateau (Huang et al., 2000). All of this supports the notion that a mid-Holocene drought existed in regions of the Chinese Loess Plateau and southern Mongolian Plateau.

This mid-Holocene drought was only the most intense and longest of a number of droughts that occurred throughout the Holocene
(Fig. 1). Seven droughts, lasting a few centuries to a few millennia, are recorded in pollen proxies in the SJC section during the Holocene. The droughts are shown by changes in pollen concentrations representing total drainage vegetation coverage, high-elevation vegetation pollen concentrations representing mainly forest vegetation coverage, and Picea-Pinus pollen content representing moisture (Fig. 3). The seven droughts were at $0-0.5 \mathrm{cal}$ ka, 1.2-1.9 cal ka, 2.7-3.2 cal ka, 5.07.2 cal ka, 8.3-8.8 cal ka, 9.2-9.7 cal ka and 10.4-11.2 cal ka, based on our chronology. A possible eighth drought occurred at $7.7 \mathrm{cal} \mathrm{ka}$. The droughts correlate well with changes in hematite-stained grains of core VM29-191 in the Northern Atlantic Ocean, a proxy of ice-rafting events and, thus, temperature (Bond et al., 2001), and with potassium ion content in the GISP2 ice core (Mayewski et al., 1997), a proxy of change in the Siberian-Mongolian High and atmospheric dust (Mayewski et al.,
2004). This supports a hemispherescale correlation of central and millennial climatic events during the present warm interglacial.

\section{REFERENCES}

An, C.-B., Feng, Z., Barton, L., 2005. Dry or Humid? Mid Holocene humidity changes in arid and semiarid China. Quaternary Science Reviews, in press Bond, G., Kormer, B., Beer, J., Muscheler, R., Evans, M. N., Showers, W., Hoffmann, S., Lotti-Bond, R., Hajdas, I. and Bonani G., 2001. Persistent solar influence on North Atlantic climate during the Holocene. Science 294, 2130-2136.

Chen, C-T. A., Lan, H-C., Lou, J-Y., Chen, Y-C., 2003 The dry Holocene Megathermal in Inner Mongolia. Palaeogeography Palaeoclimatology Palaeoecology, 193, 181-200.

Chen, F.H., Wu, W., Holmes, J.A., Madsen, D.B., Zhu, Y., Jin, M. and Oviatt, C.G., 2003. A mid-Holocene drought interval as evidenced by lake desiccation in the Alashan Plateau, inner Mongolia China. Chinese Science Bulletin, 48(14), 1401-1410.

Grunert. J., Lehmkuhl, F., Walther, M., 2000 Paleoclimatic evolution of the Uvs Nuur basin and adjacent areas (Western Mongolia). Quaternary International, 65/66: 171-192

For full references please consult:

www.pages-igbp.org/products/newsletters/ref2005_2.htm

\section{Grain-size Record of Stepwise Expansion of the Mu Us Desert for the Past $3.5 \mathrm{Ma}$}

\section{Zhongli Ding and SHILING Yang}

Institute of Geology and Geophysics, CAS, Beijing 100029, China; zlding@mail.igcas.ac.cn; yangsl@mail.igcas.ac.cn

The Mu Us Desert lies immediately north of the Loess Plateau in northern China (Fig. 1). A reconstruction of the desert environment has demonstrated that the southern margin of the desert migrated several hundred km north of its Last Glacial Maximum (LGM, 20 ka BP) limit in response to increased monsoon rainfall during the Holocene Optimum ( 8-4 ka BP) (Sun et al., 1998). However, little is known about the long-term evolution of this monsoon-sensitive environment because of the sparseness of directly extractable geological evidence of suitable type and quality to be found within it. In this report, we'll first show, on the basis of the spatial grain-size changes of three north-south loess transects across the Chinese Loess Plateau, that sand-sized particle content within loess can be used to assess the shift of the southern desert margin. We then present a

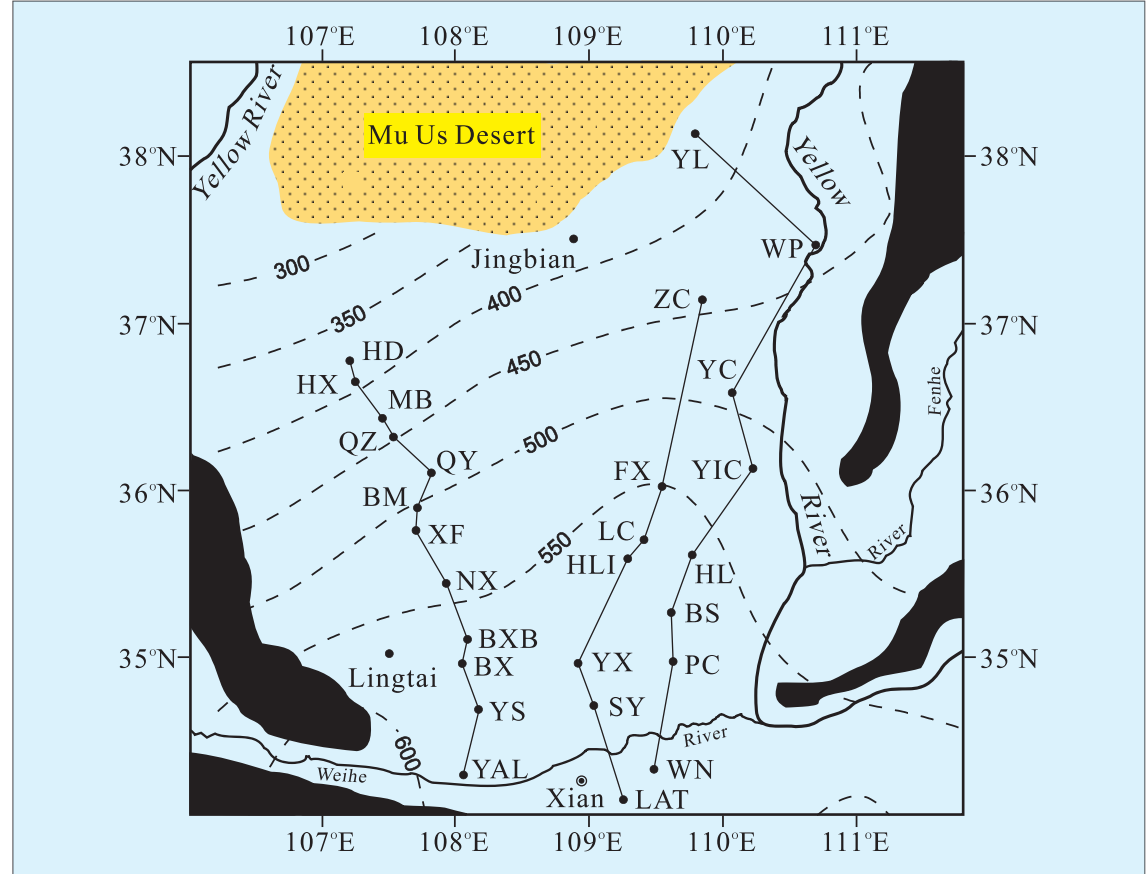

Fig. 1: The sampling localities and annual precipitation isopleths $(\mathrm{mm})$ in the Loess Plateau. grain-size record of loess-red clay deposits from the desert-loess transitional zone to provide insight into the evolutional history of the Mu Us Desert during the Plio-Pleistocene period. The three loess transects are 